\title{
Validity of Using Bamboo as Reinforcement of Concrete Beams
}

\author{
Mohammad Mohie Eldin and Eman El-Tahan
}

\begin{abstract}
Natural fibers, including the Bamboo, are environment friendly materials. They require a low degree of industrialization and a small energy for their processing and production, and hence the total fabricating cost is also low. The main purpose of this paper is to cover the lack of information about Bamboo; its mechanical properties, interaction with concrete, strength and durability, and to investigate its validity of replacing steel as a reinforcement of concrete beams. This possibility is investigated through experimental results of bamboo reinforced concrete beams compared with others reinforced using steel. The experimental results were verified and expanded using the FE package called ANSYS. In this research, the Bamboo was used without any treatment or stirrups. It was found that untreated Bamboo must not be used as reinforcement in concrete beams, although its mechanical properties may be considered as comparable to steel.
\end{abstract}

Keywords - Bamboo, Reinforcement, concrete, ANSYS.

\section{Introduction}

This template, Concrete which is considered as the main construction material has high compressive strength while its tensile strength is so weak. As a result, steel is used as reinforcement to achieve the required tensile strength. However, steel is a high cost material and disadvantageous according to its corrosion possibility. So, in the last twenty five years the principles of fiber reinforcement of brittle matrices have begun to be scientifically understood [1]. Advanced composites are now routinely used alongside with the engineering materials in a wide variety of applications due to their high specific strength, high specific modules and low thermal expansion coefficient among others [2], [3]. The use of textile materials as reinforcement for cement and concrete elements is gaining increase interest in recent years for various applications [4], [5]. One of the methods to improve the tensile strength, flexural strength, and toughness is by adding fiber reinforcement [5]. Recently, several researchers and investigators [6-9] reported very promising results of cement-based products reinforced with fabrics indicate the effect of the type of fabric as well as the material on the mechanical properties. Composite materials reinforced with natural fibers are used in both automotive and construction industries [10].

Mohammad Mohie Eldin

Structural Engineering, Faculty of Engineering, Beni-Suef University Egypt

Eman El-Tahan

Textile Engineering, Faculty of Engineering, Alexandria University Egypt
Vegetable fibers, including sisal, coconut, jute, bamboo and wood fibers, are prospective reinforcing materials and their use until now has been more empirical than technical. Vegetable fibers require only a low degree of industrialization for their processing and in comparison with an equivalent weight of the most common synthetic reinforcing fibers, the energy required for their production is small and hence the cost of fabricating these composites is also low [11]. Bamboo is a material, which has tremendous economic advantages, as it reaches its full growth in just a few months and reaches its maximum mechanical resistance in just few years. Moreover, it exists in abundance in tropical and subtropical regions of the globe [12]. Bamboos are giant grasses and not trees as commonly believed. They belong to the family of the Bambusoideae. The bamboo culm, in general, is a cylindrical shell, which is divided by transversal diaphragms at the nodes. Bamboo shells are orthotropic materials with high strength in the direction parallel to the fibers and low strength perpendicular to the fibers respectively [13]. In Southeast Asia, the use of bamboo has long proven its excellence by building houses totally constructed of natural bamboo. Durability, suitability as a good absorber of heat and access to source material made it famous and still used until now.

This research aims to study both the mechanical properties of Bamboo and to investigate the validity of using Bamboo as reinforcement in concrete beams.

\section{Testing Program}

In order to study the behavior of the bamboo as a reinforcement of concrete beams, a testing program was performed. This program consists of two stages as follows:

1. Obtaining the mechanical properties of bamboo rods through tension test.

2. Flexural strength tests of:
a) Plain concrete beams.
b) Steel-reinforced concrete beams.
c) Bamboo-reinforced concrete beams.

\section{A. Tension Test of Bamboo rods}

Specimens of 500-mm-length of diameters 6 and $12 \mathrm{~mm}$ were utilized to perform standard tension test. According to ASTM D5035-95, three specimens of each diameter were tested to investigate the mechanical properties of each type. Strain gages were used to measure and draw, directly, the stress-strain curve of the bamboo.

According to change of cross sections at both ends of the specimens when clamped to both heads of the machine, releasing of specimens occurred several times. To overcome this problem, ends of the specimen were glued using an epoxy adhesive material into steel or rubber tubes, Fig. (1). 
Proc. Of the International Conference on Advances in Civil, Structural and Construction Engineering - CSCE 2016 . Copyright (C) Institute of Research Engineers and Doctors. All rights reserved.

ISBN: 978-1-63248-101-6 doi: 10.15224/ 978-1-63248-101-6-02

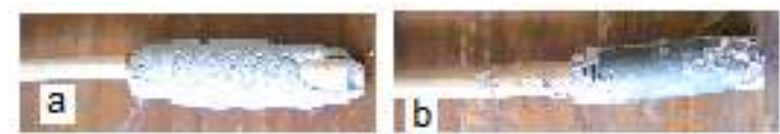

Figure 1. (a) Epoxy Adhesive Material, (b) Steel / Rubber Tubes at Ends

According to the stress-strain curve shown in Fig (2), it is obvious that the behavior of bamboo rods is, generally, nonlinear and this nonlinearity decreases with increasing the diameter. Also, tensile strength of bamboo (52-90 MPa) can be considered as comparative to that of steel, especially knowing that the used bamboo rods are not treated. Adding to these, Bamboo shows an excellent ductility (2.2-5.7\%). However, shape of failure, shown in Fig. (3), is brittle according to the presence of voids in the cross sectional area of the specimens. Fig. (4) shows microscopic views for areas of 200-micrometer-length for bamboo cross-sections of diameters 6 and $12 \mathrm{~mm}$, respectively. Two photos of each diameter were analyzed using the software "ImageJ" to get the percentages of both solids and voids in each of them. The percentages of solids were 76.186 and 71.891 (average $=74 \%$ ) for the $6 \mathrm{~mm}$-diameter slides and they were 35.401 and 60.959 (average $=48 \%$ ) for the $12 \mathrm{~mm}$-diameter slides.

Table (1) shows a comparison between the characteristics of both $6 \mathrm{~mm}$ and $12 \mathrm{~mm}$-diameter rods used in this research.

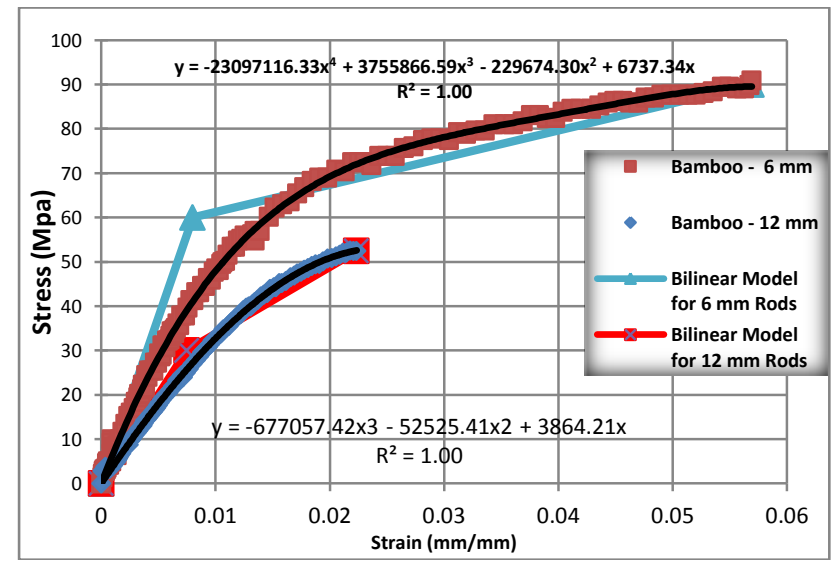

Figure 2. Stress-Strain Curve of Bamboo Sticks

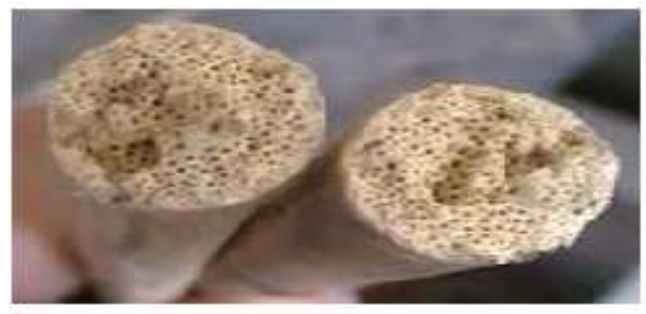

Figure 3. Brittle shape of failure.
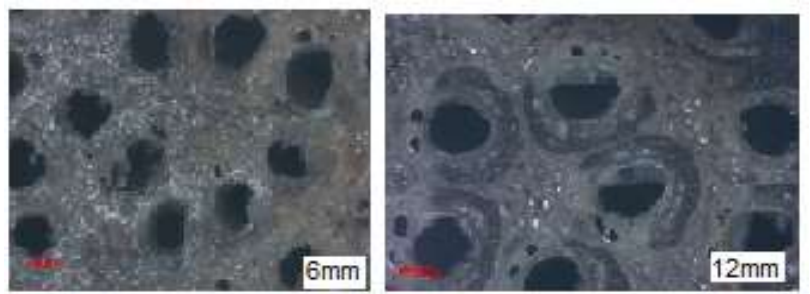

Figure 4. Microscopic Photo for area of 200-micrometer-length for $6 \mathrm{~mm}$ and $12 \mathrm{~mm}$ diameters Slide.
TABLE I. COMPARISON BETWEEN 6 MM AND 12 MM-DIAMETER RODS

\begin{tabular}{|c|c|c|c|}
\hline Item & $12 \mathrm{~mm}$ & $6 \mathrm{~mm}$ & $\begin{array}{c}\begin{array}{c}\text { Percentage of } \\
\text { increasing }\end{array} \\
\end{array}$ \\
\hline Modulus of Elasticity (MPa) & 3865 & 6756 & $75 \%$ \\
\hline Max. Strength (MPa) & 52.43 & 89.83 & $71.33 \%$ \\
\hline Max. Strain (Ductility) \% & 2.23 & 5.67 & $154 \%$ \\
\hline Average Percentage of Solids & 48 & 74 & $154 \%$ \\
\hline Average Percentage of Voids & 52 & 26 & $-48 \%$ \\
\hline ElastoPlastic Model (MPa) & $\begin{array}{c}\mathrm{Fy}=30 \\
\mathrm{Fu}=52 \\
\mathrm{E}=4000\end{array}$ & $\begin{array}{c}\mathrm{Fy}=60 \\
\mathrm{Fu}=90 \\
\mathrm{E}=7500\end{array}$ & \\
\hline
\end{tabular}

It is obvious from table (1) that bamboo rods with $6 \mathrm{~mm}$ diameter have more strength and ductility than that of 12 mm diameter rods.

As an explanation, and as a result of lateral growth of cells, increasing the diameter leads to increasing of spaces between fibers which results in considerable decreasing in both tensile strength and adhesion between fibers. Another important notice, according to the microscopic photos, is the random of the location, the shape and the size of the voids, which increases with the increasing of the diameter. This is expected to be very effective upon the behavior of Bamboo rods.

\section{B. Flexural Test of Plain/Reinforced Concrete Beams}

\section{B.1. Test Setup and Dimensions}

To get the flexural behavior of tested concrete beams, flexural testing machine was used to apply one-point loading in the mid span as shown in Fig. (5). Longitudinal and crosssectional dimensions of tested beams are shown in Fig.(6). $20 \mathrm{~mm}$ clear concrete cover is used in all directions.



Figure 5. Flexural testing machine

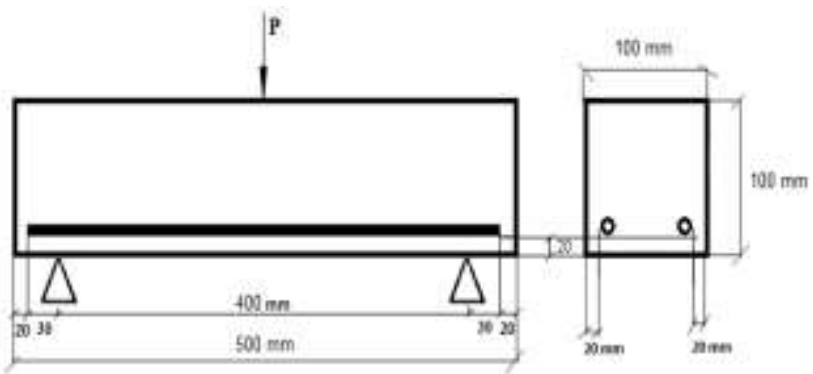

Figure 6. Dimensions of tested beams 


\section{B.2. Materials}

Concrete Compressive Strength: A compression test upon concrete cubes of size $150 \times 150 \times 150 \mathrm{~mm}$ was conducted. After casting of concrete, specimens were kept in a wet place for 24 hours and cured under water for seven days before test execution. The average compressive strength of concrete cubes $\mathrm{F}_{\mathrm{cu}}=31.5 \mathrm{MPa}$.

Steel Bars: $6 \mathrm{~mm}$ bars are used as reinforcement in steelreinforced concrete beams. Yield, failure and ultimate stresses, obtained through standard tension test, are shown in Fig. (7).

Bamboo Rods: 6 and $12 \mathrm{~mm}$ rods are used as reinforcement in bamboo-reinforced concrete beams. Mechanical properties are shown in Fig. (2) and Table (1).

\section{B.3. Arrangement of Specimens}

Different schemes of bamboo-reinforced concrete beams were prepared. These specimens were made by hand lay-up of the bamboo samples in the concrete beams. Specimens were molded and cured under water for up to seven days before testing. Table (2) shows the arrangement of the tested specimens.

TABLE II. ARRANGEMENT OF THE SPECIMENS

\begin{tabular}{|l|c|c|c|c|c|}
\hline \multirow{2}{*}{ Beam } & \multicolumn{2}{|c|}{ Number of Bars } & \multirow{2}{*}{$\begin{array}{c}\text { Reinforcement } \\
\text { Type }\end{array}$} & $\begin{array}{c}\text { Diameter } \\
(\mathbf{m m})\end{array}$ & $\begin{array}{c}\text { Clear } \\
\text { Span } \\
(\mathbf{m m})\end{array}$ \\
\cline { 2 - 4 } Lower & Upper & Non & ----- & 400 \\
\hline PC & ----- & ----- & Steel & 6 & 400 \\
\hline $\begin{array}{l}\text { RCS2- } \\
\text { 6-400 }\end{array}$ & 2 & ----- & Steel & 6 & 400 \\
\hline $\begin{array}{l}\text { RCS22- } \\
\text { 6-400 }\end{array}$ & 2 & 2 & Bamboo & 6 & 400 \\
\hline $\begin{array}{l}\text { RCB2- } \\
\text { 6-400 }\end{array}$ & 2 & ----- & Bamboo & 6 & 400 \\
\hline $\begin{array}{l}\text { RCB22- } \\
6-400\end{array}$ & 2 & 2 & Bamboo & 6 & 400 \\
\hline $\begin{array}{l}\text { RCB4- } \\
\text { 6-400 }\end{array}$ & 4 & ----- & Bamboo & 12 & 900 \\
\hline $\begin{array}{l}\text { RCB22- } \\
12-900\end{array}$ & 2 & 2 & & & \\
\hline
\end{tabular}

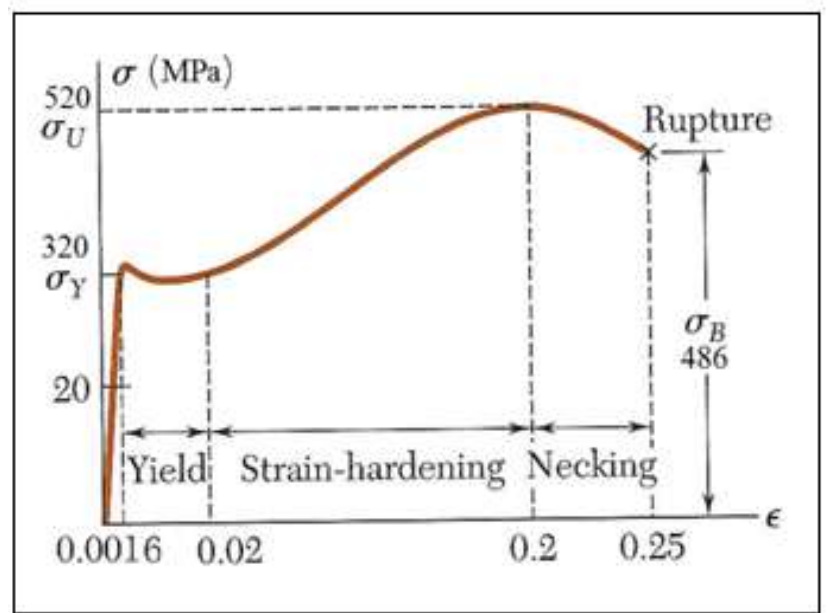

Figure 7. Stress-Strain Curve for Steel bars

\section{Finite Element Modeling}

In this study, the finite element package ANSYS is used to help in accurate understanding of the behavior of reinforced concrete beams with untreated Bamboo rods. The von Mises yield criterion is used to predict the onset of the yielding, whereas the behavior upon further yielding is predicted by the 'flow rule"' and "hardening law".

\section{A. Element Types}

Two types of finite elements, SOLID65 and LINK180, are used for 3-D modeling of the tested beams. Element SOLID65 is used for the modeling of the concrete beams while LINK180 element is used for the modeling of reinforcement bars either steel or Bamboo.

SOLID65 is defined by eight nodes having three degrees of freedom at each node: translations in the nodal $\mathrm{x}, \mathrm{y}$, and $\mathrm{z}$ directions. The solid is capable of cracking in tension and crushing in compression.

LINK180 is a uniaxial tension-compression element with three degrees of freedom at each node: translations in the nodal $\mathrm{x}, \mathrm{y}$, and $\mathrm{z}$ directions. Both elements have plasticity, large deflection, and large strain capabilities.

\section{B. Material properties}

B.1. Concrete: Stress-strain curve of concrete was modeled using the equations of Thorenfeldt et. al [14]. These equations are mainly functions in the value of the compression strength of concrete cylinder $\left(\mathrm{F}_{\mathrm{cy}}\right)$ which is approximately 0.85 of that for concrete cube $\left(\mathrm{F}_{\mathrm{cu}}\right) ;\left[\mathrm{F}_{\mathrm{cy}}=\right.$ $0.85 \mathrm{~F}_{\mathrm{cu}}=26.8 \mathrm{MPa}$ ]. Fig. (8) shows a typical RC stressstrain curve.

Additional concrete material data related to SOLID65 element have to be input; shear transfer coefficients and tensile stresses. Shear transfer coefficients range from 0.0 (representing a smooth crack or complete loss of shear transfer) to 1.0 (representing a rough crack or no loss of shear transfer). This specification may be made for both open and closed crack. Open-crack and close-crack shear coefficients are taken as 0.1 and 0.9 , respectively. Ultimate tensile strength $\mathrm{F}_{\mathrm{t}}$ is taken as $(3.15 \rightarrow 4) \mathrm{MPa}$.

When the element is cracked or crushed, a small amount of stiffness is added to the element for numerical stability. However, crushing capability was turned off to allow convergence of the models. Also, secant modulus of elasticity is used in the FE modeling instead of the initial one. Finally, Poisson's ratio is taken as 0.2.

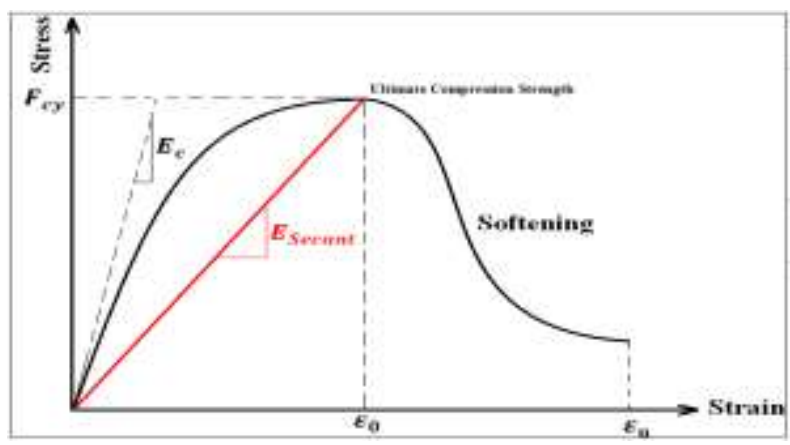

Figure 8. Typical RC Stress-Strain C 
Proc. Of the International Conference on Advances in Civil, Structural and Construction Engineering - CSCE 2016 . Copyright (C) Institute of Research Engineers and Doctors. All rights reserved.

ISBN: 978-1-63248-101-6 doi: 10.15224/ 978-1-63248-101-6-02

B.2. Steel: Multilinear isotropic hardening material is used to represent the stress-strain curve of steel bars shown in Fig. (7). Modulus of elasticity and Poisson's ratio are taken as $2 \times 10^{5} \mathrm{MPa}$ and 0.3 , respectively.

B.3. Bamboo: Although Bamboo is not an isotropic material, but when used as reinforcement, it will be subjected mainly to axial stresses and strains. So, it can be considered as isotropic without affecting the accuracy of the model. Experimental stress-strain curves of Bamboo rods are modeled as bilinear isotropic hardening materials as shown in Figure (2) and Table (1). Poisson's ratio is taken as 0.35 .

\section{Meshing}

Meshing analysis was done to obtain the acceptable size of solid elements that lead to accurate results in a minimum solution time. As a result, element size of: $(\mathrm{x} \times \mathrm{y} \times \mathrm{z}=20 \times 20 \times 10 \mathrm{~mm})$ was chosen. The total number of solid elements is 1250 while the number of link elements is 46 per reinforcement bar.

\section{Boundary conditions}

As shown in Figures (5) and (6), all the beams are simply supported. One of the two supports is modeled as roller support to only allow the movement in the direction of the beam axe (direction $\mathrm{Z}$ ), while the other is pinned support to prevent it from movement in any direction.

\section{Results and discussions}

Figures from (9) to (15) show the experimental and FE relations between the applied vertical load and the mid-span deflection for the specimens mentioned in Table (2).

The results show very good agreement between both experimental and FE models. This means that FE results can be used to investigate the validity of using Bamboo as reinforcement for concrete beams.

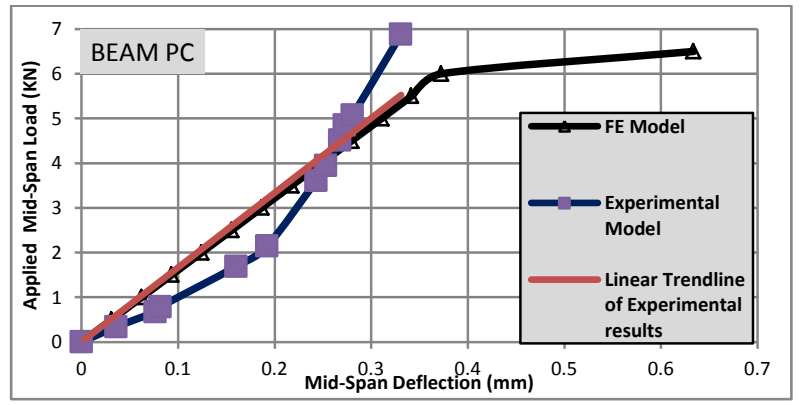

Figure 9. Load-Deflection Curve for Plain Concrete Beam PC.

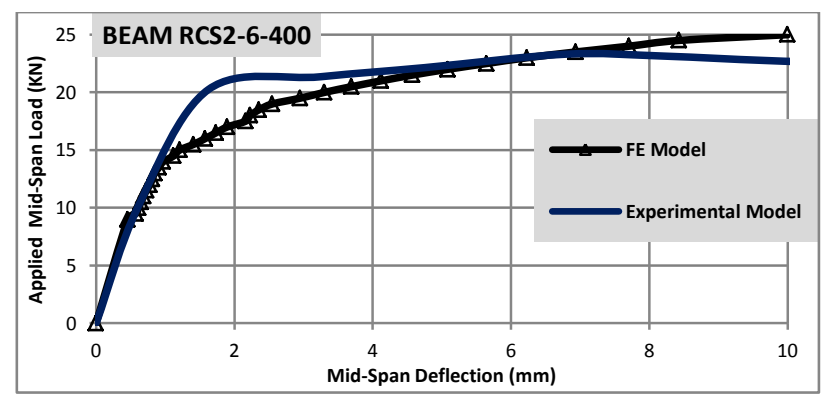

Figure 10. Load-Deflection Curve for Steel RC Beam RCS2-6-400.

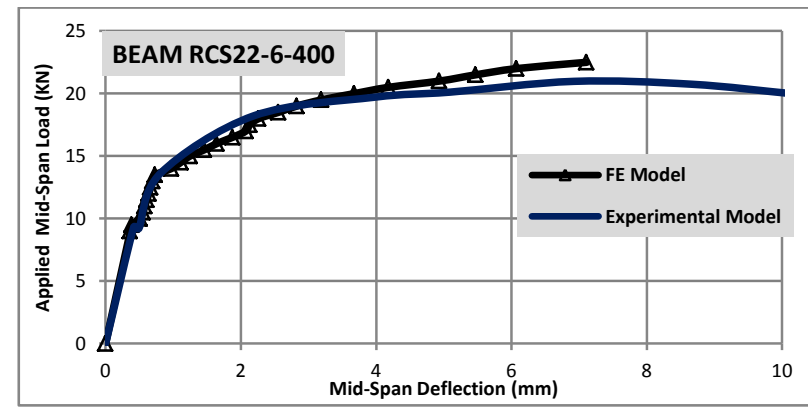

Figure 11. Load- Deflection Curve for Steel RC Beam RCS22-6-400.

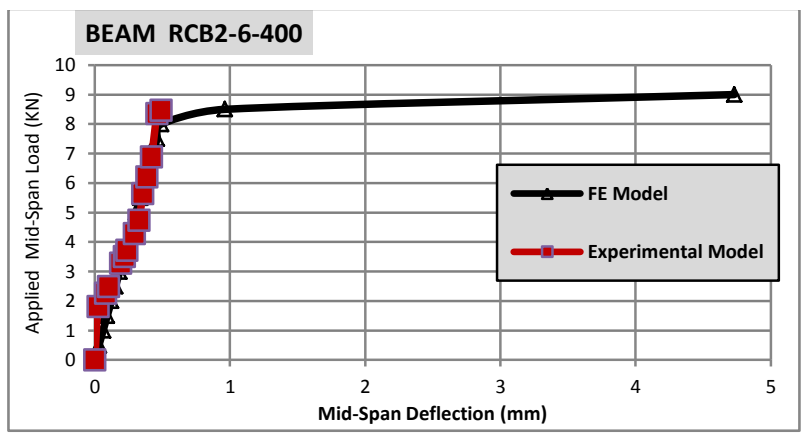

Figure 12. Load-Deflection Curve for Bamboo RC Beam RCB2-6-400.

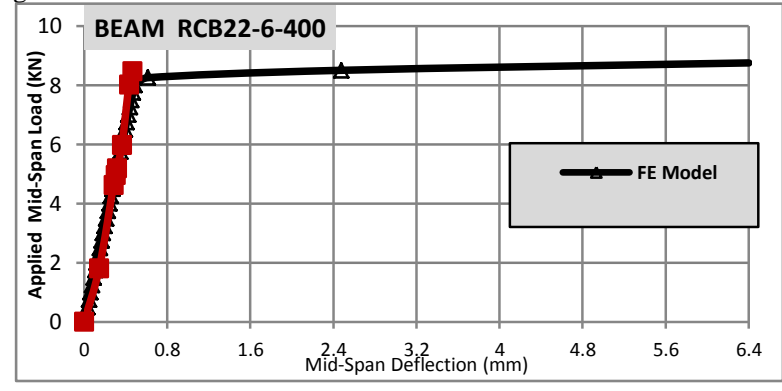

Figure 13. Load- Deflection Curve for Bamboo RC Beam RCB22-6-400.

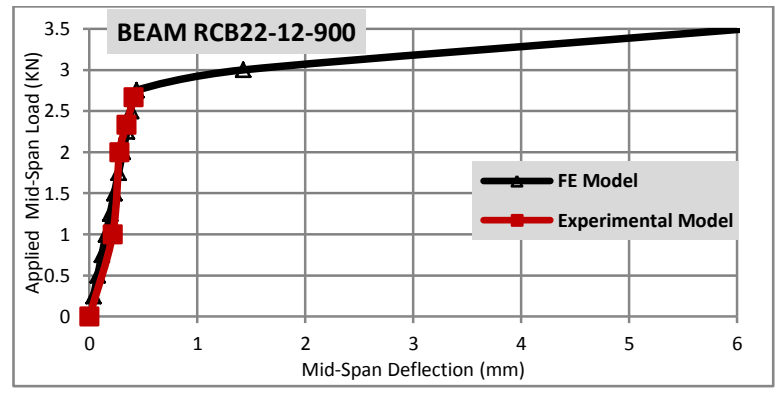

Figure 14. Load-Deflection Curve for Bamboo RC Beam RCB22-12-900.

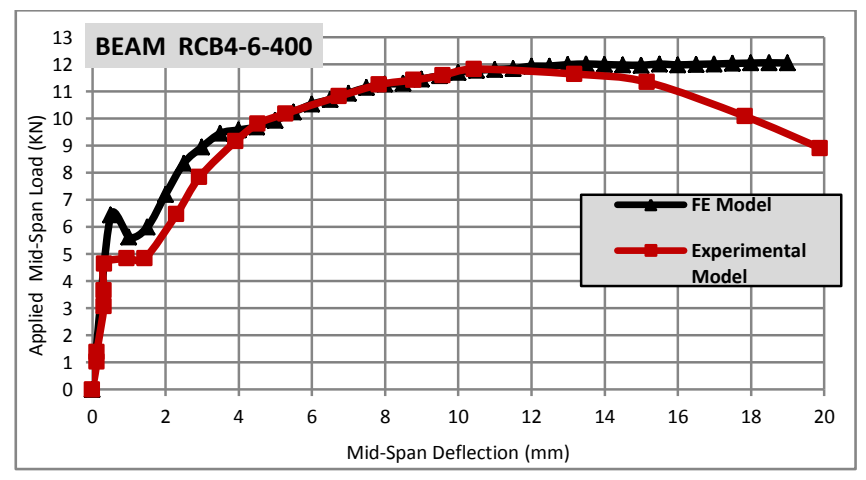

Figure 15. Load-Deflection Curve for Bamboo RC Beam RCB4-6-400. 
According to both experimental and FE results, it can be mentioned that:

1. Plain concrete (PC) beam behaves mainly linear till failure without ductility. It failed suddenly with a brittle failure, as shown in Figures (9) and (16).

2. The behavior of reinforced concrete beams with steel bars is nonlinear. Reinforcing of beams using steel bars in tension zone of area $\left(A_{s}=2 \emptyset 6 \mathrm{~mm}\right)$ equals $0.56 \%$ of the concrete cross sectional area $\left(A_{c}\right)$, with or without upper reinforcement of the same area, leads to increasing of strength and ductility about $250 \%$ and $3000 \%$, respectively, comparing with those values of the PC beam. Finally, failure is gradual and ductile and occurs after an obvious propagation of cracks. See Figures (10), (11) and (17).

3. Reinforcing of beams using Bamboo rods in tension zone of area $\left(A_{B}=2 \emptyset 6 \mathrm{~mm}\right)$ equals $0.56 \%$ of the concrete cross sectional area $\left(A_{c}\right)$, with or without upper reinforcement of the same area, leads to an average increasing of strength and ductility about $22 \%$ and 39\%, respectively. However, if $\left(A_{B}=\right.$ $2 \emptyset 12 \mathrm{~mm}=2.26 \%$ of $A_{c}$ ), the strength increases by $16 \%$ while the ductility decreases by $26 \%$. These results are due the Bamboo strength is generally more than that of the concrete, while both strength and ductility of the Bamboo decreases with increasing the diameter according to the increasing of voids ratio, as shown in Figures (2), (4) and Table (1).

4. The previous results indicate that reinforcing beams using untreated Bamboo rods has a very small effect upon both ductility and strength comparing with reinforcing using steel bars. Also, the behavior of the reinforced beams using Bamboo is linear which means that the failure is approximately brittle and the propagation of cracks is bad or does not exist, as shown in Fig. (18).

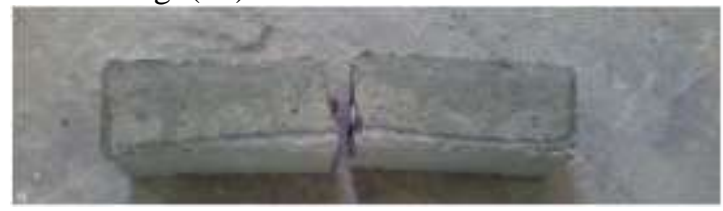

Figure 16. Fracture Shape (Brittle Failure) of PC Beam.

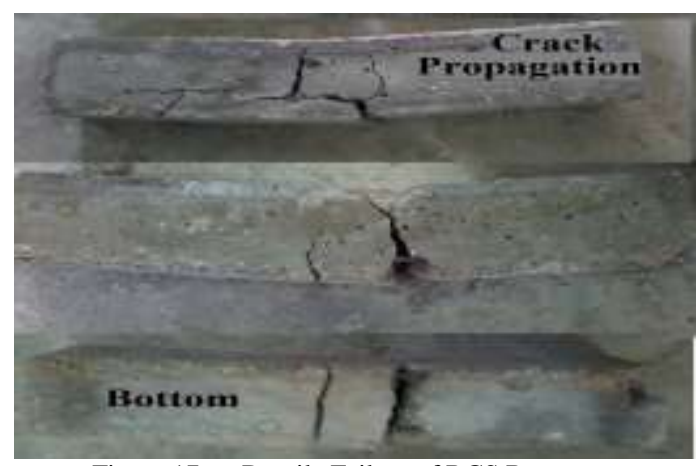

Figure 17. Ductile Failure of RCS Beams.

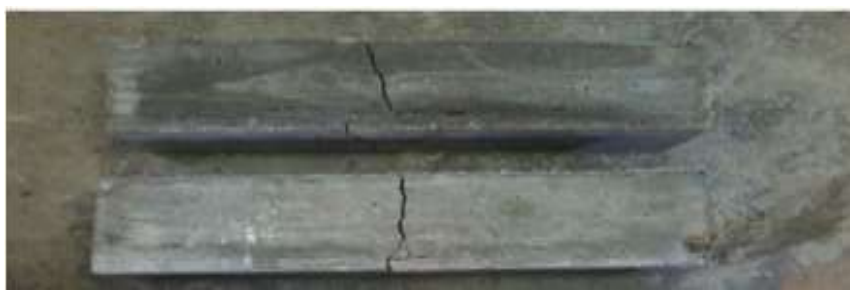

Figure 18. Failure Shapes for Bamboo Reinforced beams.

5. FE results of $\mathrm{RC}$ beams with Bamboo show nonlinear behavior while the experimental results show linear behavior, Figures from (12) to (14). This is due two reasons; the first is that the FE modeling is idealized and does not take into account the random cross sections of Bamboo including voids which result in non-homogeneous section. The second is that Bamboo is modeled as nonlinear isotropic hardening material.

6. It is believed that these results are due to the water absorption which affects the bonding strength between Bamboo bars and concrete as will be illustrated.

\section{v. Effect of water absorption}

While casting and curing of concrete, bamboo rods absorb water which leads to swelling. After curing, bamboo loses its moisture which results in shrinkage. The cycle of swelling and shrinkage not only causes cracks in concrete, but leads to serious reduction of both strength and ductility when compared with steel in concrete. Table (3) shows that as soon as the cracks initiate, Fig. (19), the stress in the Bamboo increases dramatically from $6.22 \mathrm{MPa}$ to 43.48 $\mathrm{MPa}$, and quickly passes the yield stress (60 MPa) till failure (90 MPa) in the successive two load-steps. This explains the quick failure with no ductility. So, the bond between bamboo segments and concrete has to be improved.

A proposal, to minimize the effect of absorbing water upon bond, is to enlarge the circumference or the area of the Bamboo reinforcement. To examine this, the sample RCB46-400 beam was tested. Rods of 6-mm-diameter were used since they are more stiffness, strength and ductility than 12-mm-diameter Bamboo rods. In this sample, the percentage of reinforcement of Bamboo bars was increased from $0.565 \%\left(A_{B}=2 \varnothing 6 \mathrm{~mm}\right)$ to $1.13 \%\left(A_{B}=4 \emptyset 6 \mathrm{~mm}\right)$. As mentioned before, all the models were cured for only 7 days before testing. However, the RCB4-6-400 beam was cured for 10 days before testing. It was found that the behavior of the beam changes dramatically from linear to nonlinear, as shown in Figure (15). Increasing in both strength and ductility comparing with $\mathrm{PC}$ beam is $74 \%$ and $6000 \%$, respectively. This is comparable to steel RC beams as shown in Fig. (20), especially for stiffness and ductility.

TABLE III. StRESSES IN BAMBoo IN A MODEL DURING SOLUTION

\begin{tabular}{|c|c|c|c|c|c|c|}
\hline Load-Step & $\mathbf{3 0}$ & $\mathbf{3 1}$ & $\mathbf{3 2}$ & $\mathbf{3 3}$ & $\mathbf{3 4}$ & $\mathbf{3 5}$ \\
\hline $\begin{array}{c}\text { Load } \\
(\mathbf{K N})\end{array}$ & 7.5 & 7.75 & 8.0 & 8.25 & 8.50 & 8.75 \\
\hline $\begin{array}{c}\text { Stress } \\
\text { (MPa) }\end{array}$ & 5.831 & 6.025 & 6.22 & 43.479 & 79.234 & 90 \\
\hline $\begin{array}{c}\text { Deflection } \\
(\mathbf{m m})\end{array}$ & $\mathbf{0 . 4 6 0 0 1 0}$ & $\mathbf{0 . 4 7 5 3 3 5}$ & $\mathbf{0 . 4 9 0 6 6 6}$ & $\mathbf{0 . 8 3 3 7 4 2}$ & $\mathbf{3 . 4 3 4 4 5}$ & $\mathbf{7 . 9 8 1 4 3}$ \\
\hline Stage & Normal & Normal & Normal & $\begin{array}{c}\text { First } \\
\text { Crack }\end{array}$ & $\begin{array}{c}\text { Yield of } \\
\text { Bamboo }\end{array}$ & $\begin{array}{l}\text { Failure of } \\
\text { Bamboo }\end{array}$ \\
\hline
\end{tabular}


Proc. Of the International Conference on Advances in Civil, Structural and Construction Engineering - CSCE 2016. Copyright (C) Institute of Research Engineers and Doctors. All rights reserved.

ISBN: 978-1-63248-101-6 doi: 10.15224/ 978-1-63248-101-6-02

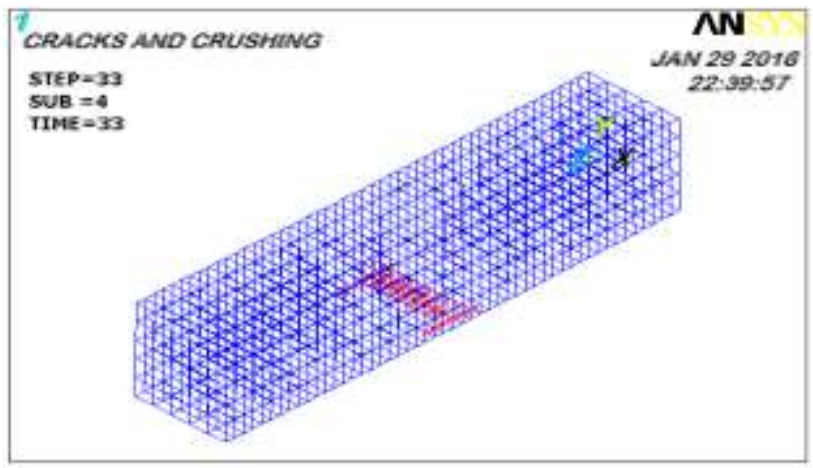

Figure 19. Initiation of Cracks.

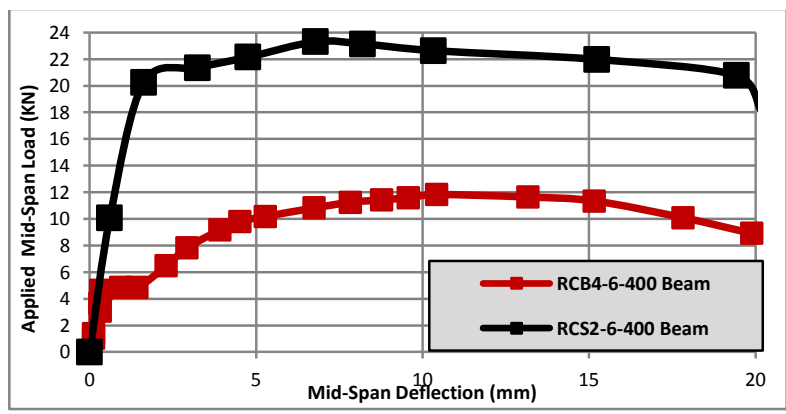

Figure 20. Comparison between RCS2-6-400 and RCB4-6-400 Beams.

\section{vi. Conclusions}

a. Experimental program and FE modeling were conducted to cover the lack of information about the structural behavior of Bamboo as reinforcement of concrete beams.

b. Bamboo has tensile strength and ductility that may support the theoretical acceptance of using Bamboo as cheap alternative to steel reinforcement.

c. Bamboo cross sections include large percentage of random voids which make Bamboo capable of absorbing water.

d. Percentage of voids increases with increasing the diameter of Bamboo. As a result, increasing of Bamboo diameter leads to decreasing in its stiffness, strength and ductility.

e. When used in concrete members, Bamboo suffers repeated cycles of expansion and contraction since it absorbs the water and, in addition, it shrinks to lose the water according to the drying of concrete. Bamboo shrinks larger and faster than concrete. This leads to quick debonding between Bamboo and concrete, which makes the goal of using it as reinforcement upon ductility and strength is unrealistic.

f. Another drawback of debonding is that the behavior of Bamboo reinforced concrete beams is linear and brittle. They fail similar to plain concrete beams; suddenly and brittle.

g. A proposal, to minimize the effect of absorbing water upon bond, is to enlarge the area (circumference) of the Bamboo reinforcement through using large number of Bamboo rods. It was found as very effective. However, more research is needed. h. Other proposals, to minimize the debonding between concrete and Bamboo, are to use an effective water-repellent treatment system and to coat Bamboo either with epoxy materials or any other chemicals, which needs more research and investigation in a future work.

i. Briefly and as a Principal, untreated Bamboo must not be used as reinforcement in concrete structures.

\section{Acknowledgment}

The authors would like to thank the team of "testing of materials laboratory" in the Faculty of Engineering, Alexandria University, for their help in conducting the experimental tests.

\section{References}

[1] R. Tolêdo, K. Joseph, K. Ghavami and G.Leslie, "The use of sisal fiber as reinforcement in Cement based composites", Revista Brasileira de Engenharia Agrícola e Ambiental, vol. 3, p p.245-256, 1999.

[2] M. El Messiry, Computer aided design for the 2-step braiding preform, Alexandria Eng. J. Xxx (3), Sec. A, 1991.

[3] M. Mohamed and L. Dickinson, "Weaving of Fabrics for Space Applications", ITEC'89, Conf. Alexandria, December 23-25, 1989.

[4] A. Peled, B. Mobasher, "Tensile behavior of fabric cement-based composites: pultruded and cast”, J. Mater. Civ. Eng. 19 (4) , pp. 340 348, 2007.

[5] A. Peled, B. Mobasher and S. Sueki, "Technology methods in textile cement-based composites", concrete science and engineering, RILEM Proc. PRO 36 pp.187- 202, 2004.

[6] H. Nordin and B. Ta“ ljsten, "Concrete beams strengthened with prestressed near surface mounted CFRP, Compos". Construct. 10 (1) pp.60-68, 2006.

[7] A. Peled, "Textile cement based composites, effects of fabric geometry, fabric type and processing", Composites in Construction 2005 - Third International Conference, Lyon, France, July 2005.

[8] A. Brueckner, R. Ortlepp and M. Curbach, "Textile reinforced concrete for strengthening in bending and shear", Mater. Struct. 39 (8) pp.741-748, 2006.

[9] B. Mobasher, J. Pahilajani and A. Peled, "Analytical simulation of tensile response of fabric reinforced cement based composites", Cement Concr. Compos. 28 (1) ,pp. 77-89, 2006.

[10] G. Angelo, T. Mark and Y. Ning," Predicting the tensile strength of natural fiber reinforced thermoplastics", Composites Science and Technology, www.elsevier.com/locate/compscitech, January 2007.

[11] M. A.Aziz, P. Paramasivam and S.L. Lee, "Natural fiber reinforced cement and concrete", London: Blackie and Son Ltd, vol. 5, chapter 3, pp. 106-140, 1984.

[12] Janssen JA., "The importance of bamboo as a building material. Bamboos current research", In: Proc of the Int Bamboo Workshop, Kerala Forest Research Institute-India \& IDRC — Canada, 1988. p. 235-41.

[13] http://en.wikipedia.org/wiki/Giant_bamboo.

[14] E. Thorenfeldt, A. Tomaszewicz, and J. Jensen, "Mechanical Properties of High Strength Concrete and Application to Design," Proceedings of the Symposium: Utilization of High-Strength Concrete", Stavanger, Norway, Tapir, Trondheim, pp. 149-159, June 1987. 